\title{
EL DICGIONARIO MÁS IMPORTANTE DE LA RAE NO ESTÁ IMPRESO
}

\section{THE MOST IMPORTANT DICTIONARY OF THE RAE HAS NOT BEEN PRINTED}

\author{
Francisco M. Carriscondo Esquivel \\ Universidad de Málaga \\ esquivel@uma.es \\ Elena Carpi \\ Universitá di Pisa \\ elena.carpi@unipi.it
}

\begin{abstract}
Resumen: En el quinto tomo del Diccionario de autoridades (1737), se anunciaba un suplemento revisado y corregido de toda la obra, plan luego desplazado por el proyecto de una segunda edición de la que sólo se publicaría el primer tomo. Por razones que se explicarán oportunamente, la publicación cabal de la segunda edición bosquejada se relegó para mejor ocasión, hasta volverse inviable. Surge la pregunta, sin embargo, de dónde quedaron los materiales que conformarían el resto de los volúmenes. A ello se da respuesta en este trabajo, luego de plantear los motivos que impidieron que el fruto de labor tan enjundiosa nunca llegara, sino parcialmente, a las planchas de la imprenta.

Palabras clave: Diccionario de autoridades; Diccionario de la lengua castellana; segunda edición; materiales inéditos; lexicografía.
\end{abstract}

Abstract: In the fifth volume of the Diccionario de autoridades (1737), a revised and corrected supplement of the entire work was announced, a plan later displaced by the project of a second edition, of which only the first volume would be published. For reasons that will be explained opportunely, the complete publication of the proposed second edition was posponed to a later date, until it was finally written off as unfeasible. The question arises, however, as to what became of the materials that were to make up the rest of the volumes. The present paper gives an answer to this question, as well as suggesting the reasons why the results of such an important piece of work only partially ever found their way into the printing shop.

Keywords: Diccionario de autoridades; Diccionario de la lengua castellana; second edition; unpublished documents; lexicography.

Recepción: 19 de julio de 2019; aceptación: 20 de agosto de 2019.

D.R. (C) 2020. Nueva Revista de Filología Hispánica Licencia Creative Commons Attribution-NonCommercial (CC BY-NC) 4.0 International 
La obra más valiosa publicada por la Real Academia Española (RAE) es la primera, habitualmente llamada Diccionario de autoridades ( $D A^{1}$ 1726-1739). Fue la elaboración de este monumento lexicográfico el fin para el que se creó, antes de nada, la institución; y es su repertorio más famoso -el Diccionario común, antes conocido como de la Real Academia Española (DRAE), ahora como de la lengua española (DLE)una reducción de los seis tomos de aquél a uno solo, toda vez que fueron suprimidas las autoridades, o textos que autorizan el uso de una determinada voz. Mientras los académicos ultimaban la edición del quinto tomo, publicado en 1737, ya pensaban en la revisión de la obra lexicográfica completa. De ahí que acordaran

volver a leer todas las voces, para ir corrigiendo qualquier defecto, que se hallasse en sus definiciones, etymologías, autoridades, acepciones, y correspondencias Latinas, y formar una planta para encontrar las que faltaban, y era precisso hallar en la particular colección de las voces peculiares de cada Provincia, de los términos de Ciencias, Artes, y Oficios mechánicos, y en la prolixa lección de libros Castellanos antiguos, y modernos, repartiendo este trabajo entre los Académicos $\left(D A^{1} 1726-\right.$ 1739 [1739], p. [xii]).

Así pues, el ritmo frenético de trabajo no decrece pese a contemplarse el final. Más bien se opta por aprovechar la inercia para trabajar simultáneamente, a partir de 1737 , con el último tomo del $D A^{1}$ (1726-1739) y la revisión profunda de la obra, en lo que en un principio iba a ser un suplemento de los seis tomos, pero que al final se convierte en una segunda edición, gracias a las correcciones de las tachas ya aludidas y al incremento de las voces nuevas mediante el procedimiento habitual de los repartimientos, entre los miembros de la Docta Casa, de las distintas combinaciones de letras (p. [xiv]). Cabe pensar entonces que, si se trataba de pulir un diamante ya de por sí bastante tallado, éste acrecentara aún más su valor. Pero todo, claro está, si se llegara hasta su consecución...

Y es que, lamentablemente, la Academia sólo llegó a publicar, en 1770 , el primer tomo de esta segunda edición, corregida y aumentada, del $D A^{1}$ (1726-1739). En seguida nos surge una pregunta: ¿por qué tardó tanto la Academia en publicarlo? La respuesta se deduce de la lectura de su "Prólogo": había otras misiones que cumplir, como la preparación de la Orthographía (1741) y un proyecto de gramática en el que se estuvo trabajando hasta 1747. Fue a partir de esta fecha cuando la institución decidió retomar el proyecto de reedición de su primer diccionario. La segunda pregunta que se nos plantea es por qué se pasa de la elaboración de un suplemento a una nueva edición. La respuesta nos la brindan, de nuevo, los propios académicos en el "Prólogo" al volumen germinal de 1770. La primera razón es que quedaban pocos juegos completos de la primera edición del 
$D A^{1}$ (1726-1739), por lo que se hacía necesario volver a editar la obra, no ya sólo un suplemento. La segunda es que en 1751 "pasaban ya de trece mil las voces y significaciones aumentadas", por lo que "había suficiente materia para un tomo de crecido volumen”, además de todo el material que se podría recoger para los siguientes volúmenes. Es así, entonces, cuando en 1753 se había decidido publicar la nueva edición, con las correcciones y el aumento del caudal léxico. Tracemos la secuencia cronológica completa, a fin de no perdernos en esta balumba de fechas:

1737 Decisión de elaborar un suplemento del $D A^{1}$ (1726-1739)

1739 Comienzo de las tareas de elaboración del suplemento del $D A^{1}$ (1726-1739)

... Ortografía (1741) y preparación de la gramática

1747 Reanudación de las tareas de elaboración del suplemento del $D A^{1}$ (1726-1739)

1751 Aumento de trece mil voces y significaciones (el suplemento en formato de "un tomo de crecido volumen")

1753 Decisión de elaborar una segunda edición, con la corrección de la primera y las nuevas incorporaciones

1770 Publicación del primer tomo de la segunda edición del diccionario: el $D A^{2}$ (1770)

Conviene reparar en este dato: el aumento en trece mil voces y significaciones de lo que sería el hipotético suplemento a la primera edición. Pues bien, de las trece mil añadiduras, dos mil doscientas corresponden a este primer tomo, tal como puede leerse en el "Prólogo" del $D A^{2}(1770$, p. x). A partir de dicha información, la tercera pregunta que se nos plantea es por qué la Docta Casa no llegó a continuar la obra. Había como mínimo diez mil ochocientos ítems nuevos que publicar en las letras restantes, además de la información nueva que se fuera recogiendo en el transcurso de los trabajos de la nueva edición. Con la información que arrojan los prólogos de las obras implicadas y otras fuentes complementarias, puede darse una respuesta a esta tercera pregunta. Hemos de abrir para ello una nueva secuencia cronológica. En 1780 se publica el Diccionario de la lengua castellana... reducido a un tomo para su más fácil uso. En su "Prólogo", la Academia apunta que, tras la publicación del primer tomo del $D A^{2}$ (1770), "continuó haciendo el mismo trabajo en la letra $\mathrm{C}$ y demás restantes" (p. [i]). Luego la preparación de la segunda edición del diccionario seguía desarrollándose. Ahora bien, de nuevo se insiste en los mismos inconvenientes que demoran su salida: "los repetidos y prolixos exâmenes, que es preciso hacer de cada uno de sus artículos" y el desempeño de "otros trabajos, propios también de su instituto" (ibid.).

Estos obstáculos han provocado la interrupción "á temporadas" y el consecuente retardo en su preparación, "más de lo que la ACADEMIA quisiera" (ibid.). A ello se suma, de nuevo, el consabido 
agotamiento de ejemplares, tanto de la primera edición como del primer tomo de la segunda. Ante esta serie de obstáculos, la Docta Casa se plantea una disyuntiva que soluciona sin necesidad de elegir entre una u otra opción de las barajadas. Es decir: ¿se seguiría con la preparación de la segunda edición del $D A^{1}$ (1726-1739)?; y, por otra parte, ¿se confeccionaría una nueva obra, de ejecución inmediata? La respuesta ya se conoce. Estamos ante la primera de las sucesivas ediciones del archiconocido Diccionario común o vulgar, con un devenir histórico que continúa hasta el presente, aunque ya no sea en papel, sino en soporte informático. Pero, de vuelta a sus orígenes, la nueva obra, de ejecución inmediata, si bien no del todo de nuevo cuño, surge, por un lado, de la reducción, a uno solo, de los seis tomos del diccionario por el que fue creada, en primera instancia, la RAE; y, por otro, de la proyectada continuación de esta obra. Por tanto, para ser más exactos, el inventario del $D R A E^{1}(1780)$ no es idéntico al del $D A^{1}$ (1726-1739), ya que, como dice la Academia en el "Prólogo" de aquella obra, se han incorporado las voces de las A y B correspondientes al primer tomo de la segunda edición, la de 1770; y, además, se han incorporado las de la letra C; tomo concluido, si bien todavía inédito.

Pero, volviendo a insistir, las opciones no eran excluyentes. Aunque la Academia sabe que su elaboración supone mucho tiempo, no ceja en su empeño por continuar la labor emprendida en $D A^{2}(1770)$. Es más, lo acabamos de leer: tenía preparados para la imprenta los materiales de la letra C, objeto del segundo tomo proyectado. Aquellos diez mil ochocientos datos nuevos que faltaban por publicar, ¿pertenecerían todos a la letra C? Está claro que no, incluso habría más novedades, correspondientes al resto de las letras. Si seguimos repasando los prólogos de las obras nos topamos con una estructura expositiva muy similar a la de la primera edición del $D R A E^{1}(1780)$, en la que se da cuenta de la paulatina incorporación de las revisiones del inventario en relación con las letras ya terminadas, según la siguiente cronología:

\begin{tabular}{ll}
\hline Diccionario & Letras revisadas \\
\hline$D R A E^{1}(1780)$ & A-C \\
$D R A E^{2}(1783)$ & A-C \\
$D R A E^{3}(1791)$ & A-F \\
$D R A E^{4}(1803)$ & A-L \\
$D R A E^{5}(1817)$ & A-P \\
\hline
\end{tabular}

La corporación no dejó de trabajar en este diccionario; al menos, por lo que dice el "Prólogo" del $D R A E^{5}$ (1817, p. [i]), hasta la letra P. Este "Prólogo" suena ya a homenaje a la primera edición del $D A^{1}$ (1726-1739) y casi a elogio fúnebre a la nonata de la segunda. Pero lo más importante para darnos cuenta de esta crónica de una muerte 
anunciada es lo que se constata en el título mismo de las ediciones reducidas. Recordemos que de la primera a la cuarta el título es Diccionario de la lengua castellana... reducido a un tomo para su más fácil uso (1780, 1783, 1791 y 1803). Sin embargo, en la quinta, la de 1817, desaparece finalmente la referencia a la reducción. ¿Qué da a pensar esta supresión? Pues que, si se desvanece el proyecto de elaborar la segunda edición del $D A^{1}$ (1726-1739), no hace falta aludir entonces a su reducción. No se puede reducir lo que no existe.

Después de esta mención, ya no hay ninguna otra en sucesivas ediciones del DRAE. La consecuente pregunta que nos surge es por qué tomó la Academia esta fatídica decisión. Conviene recordar que el $D A^{1}$ (1726-1739) es el mayor tesoro léxico de nuestra lengua, la española, y es la mejor obra que la Docta Casa ha elaborado hasta la fecha. La respuesta, una vez más, parece deducirse de los mismos prólogos que estamos citando: la continua revisión de los materiales, no sólo de lo que faltaba por publicar, sino de lo ya publicado. Conjugar lo revisado con lo ya editado y dispuesto para la imprenta era tarea complejísima. Una solución, parcial, al problema fue la confección de suplementos. En la siguiente tabla mostramos la secuencia de dichas adiciones al cuerpo del inventario, todos los cuales, menos el del $D R A E^{3}$ (1791), figuran como anexos insertos en la obra lexicográfica:

\begin{tabular}{lll}
\hline Diccionario & $\begin{array}{l}\text { Letras incorporadas } \\
\text { al inventario }\end{array}$ & Suplementos \\
\hline$D R A E^{1}(1780)$ & A-C & A-B \\
$D R A E^{2}(1783)$ & A-C & A-C \\
$D R A E^{3}(1791)$ & A-F & D-F \\
$D R A E^{4}(1803)$ & A-L & A-Z \\
$D R A E^{5}(1817)$ & A-P & A-Z \\
\hline
\end{tabular}

Por un lado, si consideraron no publicar los tomos conforme iban siendo culminados es porque, al principio, vieron más práctico introducir las novedades del diccionario maior en el minor, más que publicar una segunda edición. Pero, por otro, si decidieron continuar con ésta es porque pensaban que la dinámica de incorporar y conjugar los datos de una obra en otra les iba a funcionar. El trabajo, sin embargo, se les fue de las manos. Al hallazgo de nuevas voces e informaciones sobre las que ingresarían primero en la obra grande y luego en la reducida se suman las incorporaciones de las letras ya revisadas que iban surgiendo, por ampliación, de edición en edición, introducidas mediante suplementos que luego, por lo demás, deberían revisarse. En definitiva, una solución bastante complicada de manejar, conjugando una y otra versión de la obra lexicográfica.

Es así como se llegó, finalmente, a la conclusión de que no se podía elaborar una obra dependiente de la otra. Por eso, en algún momento 
entre la quinta $\left(D R A E^{5} 1817\right)$ y la sexta edición $\left(D R A E^{6} 1822\right)$, la institución abandona definitivamente el trabajo de esta segunda edición del $D A^{1}$ (1726-1739). El sueño se desmorona. Llegamos entonces a las últimas preguntas que podemos formularnos. Si, como hemos leído en el "Prólogo" del $D R A E^{5}$ (1817), la Academia lleva trabajado en la segunda edición del $D A^{1}$ (1726-1739) "hasta fines de la letra P" (p. [i]), ¿dónde están todos esos materiales, de la A a la P?, ¿acaso se perdieron? Era mucha la información, y perfectamente especificada, para que se perdiera del todo o, al menos, no quedara algún vestigio de ella. En algún lugar, si no se había destruido, tenía que haber quedado reflejada. Teníamos por delante, entonces, un reto: había que seguirles la pista a estos materiales, conocer su paradero.

La primera pista que podríamos seguir es aquella por la que se adivina que los materiales figuran encubiertos, al menos en parte, en las cinco primeras ediciones del DRAE que hemos venido trabajando a lo largo de nuestra exposición. Conviene realizar una investigación al respecto, de arqueología lexicográfica, a fin de observar las novedades introducidas en cada edición según las letras que ya habían sido trabajadas, tal como indica la secuencia que figura en la tabla anterior. Pero hay otra pista, más apasionante si cabe, como es el hallazgo de la documentación física de estos materiales, depositados en el Archivo de la Real Academia Española. Se trata de treinta y siete unidades documentales repartidas como siguen: nueve legajos más veintiocho cuadernos con pliegos que contienen un total de 13943 hojas en folio.

\begin{tabular}{|c|c|c|c|c|}
\hline \multicolumn{5}{|c|}{ Legajos } \\
\hline & Inicio & Fin & Conclusión & Repartimiento \\
\hline 1 & $c$ & cebada & 1780 & \\
\hline 2 & cebada & confundirse & 1780 & \\
\hline 3 & confusamente & czarina & 1780 & \\
\hline 4 & $d$ & disyunto & 1789 & \\
\hline 5 & disyunto & ezquierda & 1789 & \\
\hline 6 & $f$ & horror & 1789 & \\
\hline 7 & horror & lynce & 1789-1791 & \\
\hline 8 & $m$ & nefandísimo & $1803-1817$ & \\
\hline 9 & paredaño & prosperidad & $1803-1817$ & Francisco de S. Andrés \\
\hline & & & & Juan B. de Arriaza \\
\hline & & & & Cándido Beltrán de Caicedo \\
\hline & & & & José Bucareli \\
\hline & & & & Ramón Chimioni \\
\hline & & & & Diego Clemencín \\
\hline & & & & Martín Fernández de Navarrete \\
\hline & & & & Casimiro Flórez Canseco \\
\hline & & & & Agustín García Arrieta \\
\hline & & & & Casimiro Gómez Ortega \\
\hline & & & & Francisco A. González Oña \\
\hline & & & & Agustín J. Mestre \\
\hline & & & & José Munárriz \\
\hline
\end{tabular}




\begin{tabular}{|c|c|c|c|c|}
\hline \multicolumn{5}{|c|}{ Cuadernos } \\
\hline 1 & pinar & quedito & 1818 & $\begin{array}{l}\text { Agustín de Silva Fernández } \\
\text { de Híjar }\end{array}$ \\
\hline 2 & puño & quedito & 1818 & \\
\hline 3 & quedo & quizá o quizás & 1818 & José G. de Silva Bazán \\
\hline 4 & $r$ & rapaz & $1818-1828$ & Diego Clemencín \\
\hline 5 & rapaz & $r e^{i}$ & $1818-1828$ & José M. de Carvajal \\
\hline 6 & $r e$ & receta & $1818-1828$ & Javier de Burgos \\
\hline 7 & receta & rechoncho & $1818-1828$ & Martín Fernández de Navarrete \\
\hline 8 & rechoncho & reforma & 1828 & José M. Musso y Valiente \\
\hline 9 & reforma & registro & 1828-1829 & Juan B. de Arriaza \\
\hline 10 & registro & rejo & 1829 & Cándido Beltrán de Caicedo \\
\hline 11 & rejo & remate & 1829 & José M. Musso y Valiente \\
\hline 12 & remate & renovador & 1829 & José Bucareli \\
\hline 13 & renovador & repicar & 1829 & Juan B. de Arriaza \\
\hline 14 & repicar & rescatar & 1829 & Jerónimo del Campo y Roselló \\
\hline 15 & rescatar & restitución & 1829 & Manuel Bretón de los Herreros \\
\hline 16 & restitución & retrocesión & 1827 & Diego Clemencín \\
\hline 17 & retrocesión & reyerta & 1829 & Eusebio M. del Valle \\
\hline 18 & reyerta & robo & 1829 & Marcial Antonio López \\
\hline 19 & robo & rompedera & 1829 & José G. de Silva Bazán \\
\hline 20 & rompedera & rotar & 1829 & Diego Clemencín \\
\hline 21 & saciedad & salaz & 1829 & José de la Revilla Gironza \\
\hline 22 & salaz & saludable & 1829 & Benito Ortega Romanillos \\
\hline 23 & saludable & sanidad & 1829 & Juan B. de Arriaza \\
\hline 24 & sanidad & secuencia & 1829 & Juan P. Pérez Caballero \\
\hline 25 & secuencia & semidoble & 1829 & Ramón Feliú \\
\hline 26 & semidoble & serpiente & 1829 & José M. Musso y Valiente \\
\hline 27 & serpiente & silvestre & 1829 & José G. de Silva Bazán \\
\hline 28 & solfa & sordamente & 1829 & Vicente González Arnao \\
\hline
\end{tabular}

Los materiales comienzan por la letra $\mathrm{C}$-lo cual resulta lógico, pues la A y la B se habían publicado en el primer tomo del $D A^{2}$ (1770) - y finalizan en sordamente, en un cuaderno fechado en 1829. Por lo tanto, la labor de ejecución de esta obra no habría acabado con la letra P, tal como se afirmaba en el "Prólogo" del $D R A E^{5}$ (1817). El abandono definitivo del proyecto se efectuó en 1829, es decir, un poco más allá de 1822 , fecha de publicación de la sexta edición del $D R A E$. La transición entre la elaboración del último de los legajos y los cuadernos responde al proceder metodológico, habitual en la Academia, de los repartimientos entre sus miembros. En la eficacia de la colaboración radica la celeridad en la entrega de los materiales, los cuales, por lo demás, adolecen de combinaciones sin cubrir, especialmente en el final de la $Q$ y la $R$ y comienzo y final de la $S$.

Por su importancia, puede decirse objetivamente que estamos ante unos materiales de enorme impacto para la comunidad hispánica en general, un monumento filológico desconocido que estamos analizando gracias a la autorización expresa de la RAE. Su estudio será un revulsivo para la investigación historiográfica, debido a que 
abre nuevas líneas de trabajo y perspectivas en el conocimiento de la historia de la lexicografía española. También de su literatura, por la profusión de fuentes manejadas por los académicos. El análisis de la documentación supondrá la necesidad de acometer una revisión profunda de la investigación diccionarística de los siglos XVIII y XIX elaborada hasta ahora. No en vano estamos ante el diccionario más importante de la RAE, desgraciadamente no finalizado y parcialmente impreso, con el mayor grueso de su contenido sin editar.

\section{REFERENCIAS}

Real Academia Española 1726-1739. Diccionario de la lengua castellana, en que se explica el verdadero sentido de las voces, su naturaleza y calidad, con las phrases o modos de hablar, los proverbios o refranes, y otras cosas convenientes al uso de la lengua [Diccionario de autoridades], Francisco del Hierro, Madrid (ts. 1-2); Imprenta de la Real Academia Española, por la Viuda de Francisco del Hierro (t. 3); Imprenta de la Real Academia Española, por los Herederos de Francisco del Hierro (ts. 4-6).

Real Academia Española 1741. Orthographía española compuesta y ordenada por la Real Academia Española, Imprenta de la Real Academia, Madrid.

Real Academia Española 1780. Diccionario de la lengua castellana compuesto por la Real Academia Española, reducido a un tomo para su más fácil uso, Joaquín Ibarra, Madrid.

Real Academia Española 1783. Diccionario de la lengua castellana compuesto por la Real Academia Española, reducido a un tomo para su más fácil uso, $2^{\mathrm{a}}$ ed. Joachín Ibarra, Madrid.

Real Academia Española 1791. Diccionario de la lengua castellana compuesto por la Real Academia Española, reducido a un tomo para su más fácil uso. Tercera edición, en la qual se han colocado en los lugares correspondientes todas las voces de los suplementos, que se pusieron al fin de las ediciones de los años de 1780 y 1783, y se han intercalado en las letras D.E. y F. nuevos artículos, de los quales se dará un suplemento separado, $3^{\mathrm{a}}$ ed. Viuda de Joaquín Ibarra, Madrid.

Real Academia Española 1803. Diccionario de la lengua castellana, compuesto por la Real Academia Española, reducido a un tomo para su más fácil uso, $4^{\mathrm{a}} \mathrm{ed}$. Viuda de Ibarra, Madrid.

Real Academia Española 1817. Diccionario de la lengua castellana, por la Real Academia Española, $5^{\text {a }}$ ed. Imprenta Real, Madrid.

Real Academia Española 1822. Diccionario de la lengua castellana, por la Real Academia Española, $6^{\text {a }}$ ed. Imprenta Nacional, Madrid. 